\title{
Calcium sulfate dihydrate (gypsum) scale inhibition by PAA, PAPEMP, and PAA/PAPEMP blend
}

\author{
Z. Amjad,* R. T. Landgraf and J. L. Penn \\ Walsh University, Division of Mathematics and Sciences, North Canton OH 44720, USA. \\ E-mail:zamjad@walsh.edu
}

\begin{abstract}
The effects of poly(acrylic acid), PAA, polyamino polyether methylene phosphonic acid, PAPEMP, and PAA / PAPEMP blend on calcium sulfate dihydrate (gypsum) are reported in this paper. It has been found that gypsum inhibition by PAA increases with increasing PAA concentration. Among the various phoshonates (i.e., aminotris(methylene phosphonic acid), AMP; hydroxyphosphono acetic acid, HPA; hydroxyethylidene 1,1-diphosphonic acid, HEDP; 2-phosphonobutane 1,2,4-tricarboxylic acid, PBTC; and polyether polyamino phosphonic acid, PAPEP) evaluated, PAPEMP shows the best inhibition for gypsum precipitation. It has also been observed that presence of PAPEMP exhibits synergistic effect on the performance of PAA. Results on calcium ion compatibility of various phosphonates show that PAPEMP compared to other phosphonates tested show higher tolerance to calcium ions.
\end{abstract}

Keywords: calcium sulfate dihydrate, precipitation, inhibition, polymer, phosphonates.

Received: December 14, 2013.

doi: $10.17675 / 2305-6894-2014-3-1-035-047$

\section{Introduction}

Industrial water systems operated on poorly treated feed water are often plagued by deposition of undesirable materials on equipment surfaces [1]. These deposits can be categorized into the following four groups: a) mineral scales, i.e., $\mathrm{CaCO}_{3}, \mathrm{BaSO}_{4}, \mathrm{Ca}_{3}\left(\mathrm{PO}_{4}\right)_{2}$, etc., b) corrosion products, i.e., $\mathrm{Fe}_{2} \mathrm{O}_{3}, \mathrm{Fe}_{3} \mathrm{O}_{4}, \mathrm{ZnO}, \mathrm{CuO}$, etc., c) microbiological mass, and d) suspended matter, i.e., silt, clay, precipitated salts, etc. Scale deposits, depending on their mode of formation, may be distinguished in two categories: Salts depositing more or less selectively onto the surfaces of the equipment in contact with the aqueous fluids (usually at elevated temperature) and precipitates accumulating because of sedimentation or transport by fluid flow. As a rule, in this latter case the deposits are formed in the bulk spontaneously due to the increase of the solution supersaturation, or they form as corrosion by-products which at a second stage they sediment out. Among the various strategies adopted to retard or prevent scaling is the use of chemical additives $[2,3]$ which, depending on their chemistry and the nature of the solids forming, inhibit nucleation (threshold inhibitors [4]), crystal growth or both [5]. Because of the fact that scale deposits are crystalline with a surface charge which is either directly or indirectly $\mathrm{pH}$ dependent, the chemical additives depending on the extent of ionization of their functional groups cause 
changes in the distribution of electrical charges on the surface of the suspended particles, thus determining the stability of the respective suspensions.

Calcium sulfate is one of the most commonly encountered scale deposits and occurs in three different crystalline forms; calcium sulfate dihydrate (gypsum), $\mathrm{CaSO}_{4} \cdot 2 \mathrm{H}_{2} \mathrm{O}$; calcium sulfate hemihydrate (plaster of Paris), $\mathrm{CaSO}_{4} \cdot 1 / 2 \mathrm{H}_{2} \mathrm{O}$; and calcium sulfate anhydrite $\left(\mathrm{CaSO}_{4}\right)$. In cooling water and reverse osmosis (RO) based desalination systems, gypsum is the most commonly encountered calcium sulfate scale whereas $\mathrm{CaSO}_{4} \cdot 1 / 2 \mathrm{H}_{2} \mathrm{O}$ and $\mathrm{CaSO}_{4}$ are the most frequently formed salts in high temperature processes such as multi-stage distillation and geothermal.

During the last three decades researchers have proposed several approaches for controlling scale formation including the use of acid, chelant, ion exchanger, or inhibitors [6]. The most promising scale control method involves using sub-stoichiometric dosages, especially a few parts per million ( $\mathrm{ppm})$, to the feed water either non-polymeric, e.g., phosphonate, phosphonocitric acid, condensed phosphate or polymeric additives, e.g., homopolymers of acrylic acid, methacrylic acid, maleic acid, and copolymers containing monomers of different functional group. Studies of scale inhibitors have shown that polymer effectiveness as scale inhibitor depends upon several factors including molecular weight, type and amount of monomers, and stability of polymers under thermal stress. Typically, an effective scale inhibitor contains at least one of the following functional groups: carboxyl, $-\mathrm{COOH}$; amide, $-\mathrm{CONH}_{2}$; sulfonic, $-\mathrm{HSO}_{3}$; ester, $-\mathrm{COOR}$; phosphonic acid, $-\mathrm{PO}_{3} \mathrm{H}_{2}$, etc. Such additives are primarily designed to interact with cations present on the mineral surface. In many cases, the presence of scale inhibitors may cause modifications of the crystal habit of the precipitating particles reducing their ability to adhere to the equipment surfaces [7]. In addition, various factors (e.g., water chemistry, types and concentration of flocculants, biocides, trivalent metal ions) also play important role in the efficient operation of industrial water systems $[8,9]$.

The influence of low dosages (few ppm) of polymeric and non-polymeric additives on both the rate and crystal modification of gypsum has been the subject of numerous investigations. Amjad [10] showed that polymeric additives containing $-\mathrm{COOH}$ group such as poly(acrylic acid), PAA; poly(maleic acid), PMA; and poly(itaconic acid), PIA; were particularly effective as gypsum growth inhibitors. Oner et al. [11] arrived at similar conclusions after studying the effect of various acrylic acid based copolymers as gypsum scale inhibitors. In another study Dogan et al. [12] using the spontaneous precipitation method, investigated the influence of poly(ethylene oxide)-block-poly(methacrylic acid) polymers as gypsum growth inhibitors. Results of their study reveal that inhibition increases with acid content of the polymer. Senthilmurugan and his co-workers [13] in their study on the evaluation of maleic acid:acrylic acid and maleic acid:acrylamide copolymers reported that these copolymers are effective gypsum scale inhibitors.

Recently, polyamino polyether methylene phosphonate, (PAPEMP); amino tris(methylene phoshphonic), (ATP); and PAA have been evaluated as $\mathrm{CaCO}_{3}$ scale inhibitors [14]. Results of this study reveal that addition of these additives to $\mathrm{CaCO}_{3}$ supersaturated 
solution not only affects growth kinetics but also influences $\mathrm{CaCO}_{3}$ morphology. In the present work, three inhibitors namely, PAA, PAPEMP, and PAA/PAPEMP blend have been evaluated for gypsum scale inhibition by spontaneous precipitation method. For performance comparison, commonly used phosphonates, i.e., aminotris(methylene phosphonic acid, AMP; hydroxyphosphono acetic acid, (HPA); hydroxyethylidene 1,1-diphosphonic acid, HEDP; and 2-phosphono butane 1,2,4-tricarboxylic acid, (PBTC); were also investigated. In addition, optical microscopy was used to study crystal morphology.

\section{Experimental}

\subsection{Materials}

Grade A glassware and analytical grade chemicals were used. Stock solutions of calcium chloride and sodium sulfate were prepared from the respective crystalline solids (Merck) using distilled water, filtered through $0.22 \mu \mathrm{m}$ filter paper and standardized as described previously [7]. The additives tested were commercial materials. Inhibitor stock solutions were prepared on a dry weight basis. The desired concentrations of the inhibitor were obtained by dilution. Table 1 lists the additives tested.

\subsection{Calcium sulfate nucleation and crystal growth}

Supersaturated solutions of calcium sulfate for precipitation experiments were prepared by adding a known volume of stock solutions of sodium sulfate and inhibitor solutions to glass bottles containing known volume of distilled water maintained at $66^{\circ} \mathrm{C}$. Following temperature equilibration, a known volume of calcium chloride stock solution was added in such amount that the final $\mathrm{CaSO}_{4}$ solution concentration was $45.0 \mathrm{mM}$. The total volume of the supersaturated solutions containing varying concentrations of the test inhibitors was $100 \mathrm{~mL}$. Precipitation in these solutions was monitored by analyzing aliquots of the filtered $(0.22 \mu \mathrm{m}$ filter paper) solution for calcium by EDTA titrations. The $\mathrm{pH}$ value of the calcium sulfate supersaturated solution was adjusted to $7.00 \pm 0.05$ by the addition of standard $\mathrm{HCl}$ and/or $\mathrm{NaOH}$ solutions as needed.

\subsection{Inhibitor performance}

The performance of additive as calcium sulfate inhibitor was calculated using equation (1):

$$
\% \text { Inhibition }=\left[(\mathrm{Ca})_{\mathrm{e}}-(\mathrm{Ca})_{\mathrm{f}}\right] /\left[(\mathrm{Ca})_{\mathrm{i}}-(\mathrm{Ca})_{\mathrm{f}}\right] \text {, }
$$

where:

$(\mathrm{Ca})_{\mathrm{e}}=$ Concentration of calcium in the filtrate in the presence of inhibitor at $24 \mathrm{hr}$.

$(\mathrm{Ca})_{\mathrm{f}}=$ Concentration of calcium in the filtrate in the absence of inhibitor at $24 \mathrm{hr}$.

$(\mathrm{Ca})_{\mathrm{i}}=$ Concentration of calcium at the beginning of the experiment.

At the end of experiments solids samples of precipitates were collected for characterization by optical microscopy. 
Table 1. Additives tested.

\begin{tabular}{llccc}
\hline \multicolumn{1}{c}{ Additive } & $\begin{array}{c}\text { Functional } \\
\text { Group }\end{array}$ & $\begin{array}{c}\text { Ionic } \\
\text { Charge* }\end{array}$ & $\begin{array}{c}\text { Molecular } \\
\text { Weight }\end{array}$ & Acronym \\
\hline Poly(acrylic acid) & $-\mathrm{COOH}$ & Anionic & $\sim 2,000$ & PAA \\
\hline Poly(methacrylic acid) & $-\mathrm{COOH}$ & Anionic & $\sim 6,000$ & PMAA \\
\hline Poly(2-ethyloxazoline) & Neutral & 5,000 & PEOX \\
\hline Lignosulfonate & $-\mathrm{COOH}$ & Anionic & 3,100 & LS \\
\hline Aminotris(methylene phosphonic acid) & $-\mathrm{OH}$ & Anionic & 299 & AMP \\
\hline Hydroxyethylidene 1,1-diphosphonic acid & $-\mathrm{PO}_{3} \mathrm{H}_{2}$ & Anionic & 206 & HEDP \\
\hline $\begin{array}{l}\text { Hydroxyphosphono acetic acid } \\
\text { 2-phosphonobutane 1,2,4-tricarboxylic }\end{array}$ & $-\mathrm{COH}_{2}$ & & & HPA \\
\hline $\begin{array}{l}\text { acid } \\
\text { Polyoxyethylene-polypropylene-block }\end{array}$ & $-\mathrm{CO}_{3} \mathrm{H}_{2}$ & Anionic & 156 & EOH \\
\hline
\end{tabular}

*pH of work solution, scaling index (IP/Ksp) for gypsum (2.09).

\subsection{Calcium-inhibitor salt precipitation}

The Ca-I (inhibitor) salt formation or calcium ion tolerance experiments were performed in glass bottle ( $125 \mathrm{~mL}$ capacity) placed in a double-walled glass cell maintained at $25^{\circ} \mathrm{C}$. The test solutions (total volume $100 \mathrm{~mL}$ ) were prepared by adding known volumes of stock solution $(0.1 \%)$ of inhibitor to a known volume of water in the glass bottle. After allowing the inhibitor solution to equilibrate at the experimental temperature for at least 30 minutes, the solution $\mathrm{pH}$ was adjusted to 9.00 using standard dilute solutions of $\mathrm{HCl}$ and/or $\mathrm{NaOH}$. Next, $2.50 \mathrm{~mL}$ of $0.25 \mathrm{M} \mathrm{CaCl}_{2}$ solution were added to the inhibitor solution. The solution $\mathrm{pH}$ was quickly re-adjusted to the required value with the addition of standard solution of $\mathrm{NaOH}$ as needed. The bottles were capped and continuously stirred with stirring bars and magnetic stirrers. At known time intervals (typically 30 minutes) transmittance readings were taken using Brinkmann Colorimeter Model 901 equipped with a fiber optic probe. Duplicate/triplicate experiments were run to check data reproducibility. In order to avoid faulty signal, extreme care was taken to eliminate air bubbles in the solutions, especially in the vicinity of the fiber optic probe. 


\section{Results and Discussion}

In domestic and industrial applications, additives i.e., $-\mathrm{COOH}$ group containing polymers, phosphonates, polyphosphates, etc., are used for a variety of reasons but most importantly they are used as scale inhibitors, dispersants, and anti re-deposition agents. Additives prevent scale formation either by adsorbing onto crystal growth sites of micro-crystallites thereby interfering with crystal growth or by retarding or completely suppressing the formation of the critical nuclei in the supersaturated fluid. Adsorption at specific sites of the growing crystals may result to changes in crystal morphology depending on the slower growing crystal faces.

\subsection{Gypsum nucleation and crystal growth inhibition by additives}

\subsubsection{Homopolymers performance}

During the last three decades a variety of homopolymers have been developed and are currently used as components of water treatment formulations. These polymers include: $a$ ) anionic inhibitors containing $-\mathrm{COOH}$ and $-\mathrm{SO}_{3} \mathrm{H}$ groups, i.e., poly(acrylic acid), PAA; poly(maleic acid), PMA; poly(aspartic acid), PAS; poly(methacrylic acid), PMAA; poly(acrylamide-2-methylpropane sulfonic acid), PSA; lignosulfonate, LS; and $b$ ) nonionic, i.e., poly(acrylamide, PAM; poly(2-ethyloxazoline), PEOX. Using the experimental procedure described above, performance of three different synthetic polymers, namely, PAA, PMAA, and PEOX and LS (natural) as gypsum inhibitors was investigated. Figure 1 presents inhibition data at $24 \mathrm{~h}$, calculated according to equation (1), for experiments carried out in the presence of varying polymer concentrations. There are two points worth noting: a) gypsum inhibition increases with increasing polymer concentration and $b$ ) $-\mathrm{COOH}$ group containing polymers, i.e., PAA, PMAA, exhibits better inhibitory activity compared to polymers containing $-\mathrm{SO}_{3} \mathrm{H}$ (LS); and non-ionic group (PEOX). For example, $\% I$ values obtained in the presence of $2.0 \mathrm{mg} / \mathrm{L}$ PAA and PMAA are $94 \%$ and $31 \%$, respectively. The observed mediocre performance shown by PMAA may due to poor adsorption of PMAA on gypsum crystallites.

The influence of polymer architecture (monomer type, monomer ratio, molecular weight, manufacturing process, etc.) has been the subject of numerous investigations. Ahmad et al. [15] in their study on the influence of sodium poly(acrylate) reported that addition of low levels of polymer to gypsum supersaturated solution affects induction time. Results of this study also reveal that with increasing temperature and supersaturation, the induction time decreases and the growth rate increases. Similar observations were also noted by Amjad and Hooley [16] in their seeded growth study on the evaluation of homoand co-polymers as gypsum crystallization inhibitors. It is interesting to note that whereas polymer containing $-\mathrm{SO}_{3} \mathrm{H}$ group, i.e., LS show poor performance compared to PAA as gypsum growth inhibitors (Fig. 1), interestingly, LS has been reported to perform better than PAA in dispersing iron oxide particles in aqueous solution [17]. As illustrated in Fig. 1, PEOX compared to PAA is an ineffective gypsum inhibitor. The poor performance 
observed for PEOX may be attributed to poor adsorption and/or interaction of non-ionic group present in PEOX with the calcium ion present on the gypsum crystallites. It is worth pointing out whereas PEOX exhibits poor performance as gypsum inhibitor, PEOX, has been reported to show excellent performance as silica polymerization inhibitor [18]. Thus, it is clear from the data presented in Fig. 1 that functional group present in the polymer plays an important role in imparting inhibitory activity to the polymer.

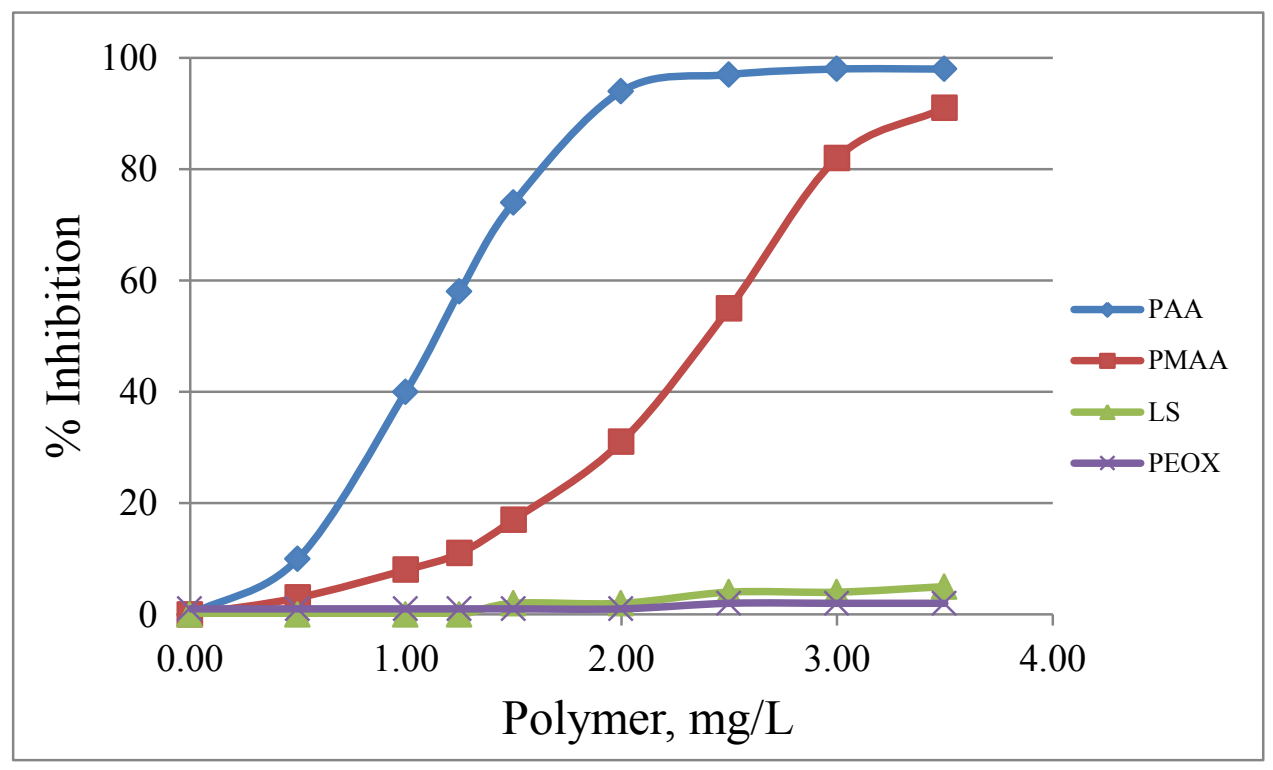

Figure 1. Gypsum inhibition in the presence of varying concentration of polymers.

\subsubsection{Phosphonates performance}

Organophosphorous compounds form a broad family of chemicals which find applications in a variety of industrial processes including crude oil production, pigment dispersion, electroplating, pulp and paper slurries, scale removal and industrial water treatment [19]. In biological systems phosphonates have been shown to decrease tartar build-up on tooth enamel and assist in preventing kidney stones [20]. For their in vitro application, phosphonates are best known of their ability to block bone resorption, treating afflictions, such as Paget's disease, hypercalcemia of tumor origin and in other bone resorptive process disorders such as osteoporosis [21]. In water treatment processes, phosphonates are used for a variety of reasons. More important, they inhibit the formation of scale forming salts and control steel corrosion. Phosphonates are also used to sequester metal ions such as iron, aluminum, copper, manganese, and zinc. Additionally, phosphonates exhibit some dispersancy activity towards suspended matter such as clay, silt, calcium carbonate, etc. Although there are many phosphonates available, six of the most commonly used phosphonates in water treatment formulations are: aminotris(methylene phosphonic acid), AMP; hydroxyethylidene 1,1-diphosphonic acid, HEDP; hydroxyphosphono acetic acid, HPA; 2-phosphonobutane 1,2,3-tricarboxylic acid, PBTC; and polyamino polyether phosphonic acid, PAPEMP. 


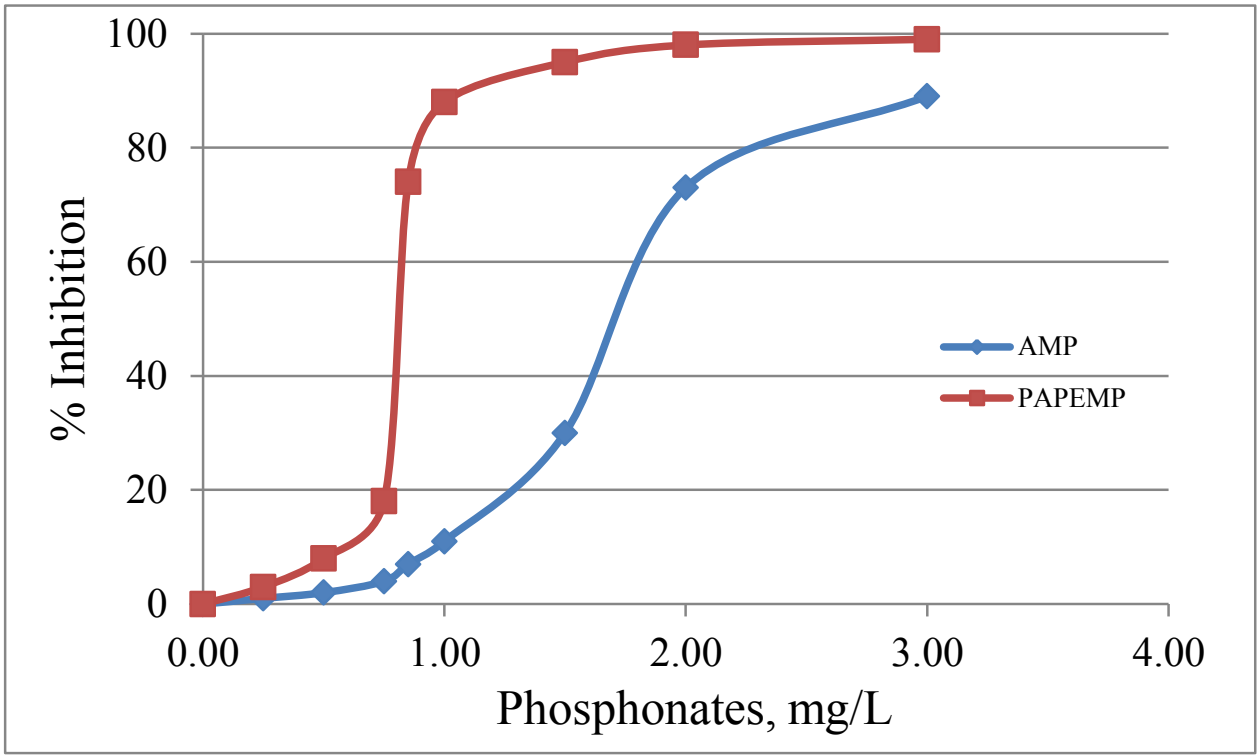

Figure 2. Plots of gypsum inhibition (\%) in the presence of varying concentrations of AMP and PAPEMP.

Figure 2 presents $\%$ inhibition data as a function of PAPEMP dosage. It can be seen that $\% I$ value increases with increasing PAPEMP concentration. For example, $\% I$ values obtained in the presence of $0.25 \mathrm{mg} / \mathrm{L}$ PAPEMP is 3\%. As noted in Fig. 2, increasing the PAPEMP dosage by twofold, i.e., 0.25 to $0.50 \mathrm{mg} / \mathrm{L}$, exhibits negligible influence on PAPEMP performance as a gypsum inhibitor. Further increase in PAPEMP concentration from 0.50 to $0.75 \mathrm{mg} / \mathrm{L}$ shows significant improvement in PAPEMP performance and at $1.0 \mathrm{mg} / \mathrm{L},>85 \%$ inhibition is obtained. In order to study the impact of ethylene oxidepropylene oxide block copolymer (EOPOP), a series of precipitation experiments were carried out in the presence of varying concentration of EOPOP. As illustrated in Fig. 2, EOPOP is an ineffective gypsum inhibitor. For example, $\% I$ value obtained in the presence of $2 \mathrm{mg} / \mathrm{L}$ is $<2 \%$ and a further increase in EOPOP concentration by fivefold, i.e., 2 to $10 \mathrm{mg} / \mathrm{L}$, does not exhibit any improvement in POPOP performance. It is evident from Fig. 2 that excellent performance shown by PAPEMP is due to the presence of four $-\mathrm{PO}_{3} \mathrm{H}_{2}$ groups and not the polyether moiety present in PAPEMP.

In order to study the influence of phosphono group present in the inhibitors, a series of experiments were carried out with varying dosages of AMP, an inhibitor containing three phosphono groups. It is evident that PAPEMP exhibits excellent performance compared to AMP in inhibiting gypsum precipitation. For example, $\% I$ values obtained for AMP at $1.0 \mathrm{mg} / \mathrm{L}$ is $<12 \%$ compared to $88 \%$ obtained for PAPEMP. The observed excellent performance shown by PAPEMP compared to AMP may be attributed to increased number of phosphono groups (four in PAPEMP $v s$. three in AMP) and/or phosphonate groups separated by the polyether in PAPEMP.

The effect of $-\mathrm{COOH}$ and/or $-\mathrm{OH}$ groups present in the phosphonates, i.e., HPA, PBTC, on gypsum inhibition was also studied. Figure 3 presents data collected in the presence of varying concentrations of phosphonates. It can be seen that in the presence of 
$1.0 \mathrm{mg} / \mathrm{L}$ phosphonates, HPA and PBTC show poor performance $(<3 \%$ inhibition) as gypsum inhibitors. As may be seen, increasing the phosphonates concentration by three fold, i.e., 1.0 to $3.0 \mathrm{mg} / \mathrm{L}$, increases $\% I$ for HPA from $1 \%$ to $8 \%$ compared to $4 \%$ and $56 \%$ obtained for PBTC. It is clear from the data that PBTC performs better than HPA in preventing gypsum precipitation. Figure 3 also presents performance data for PAPEMP. It is evident from Fig. 3 that PAPEMP is a superior gypsum inhibitor. Based on the data presented, the ranking of the phosphonates in terms of decreasing effectiveness is: PAPEMP $>>$ PBTC $>>$ HPA $>$ control (no phosphonate).

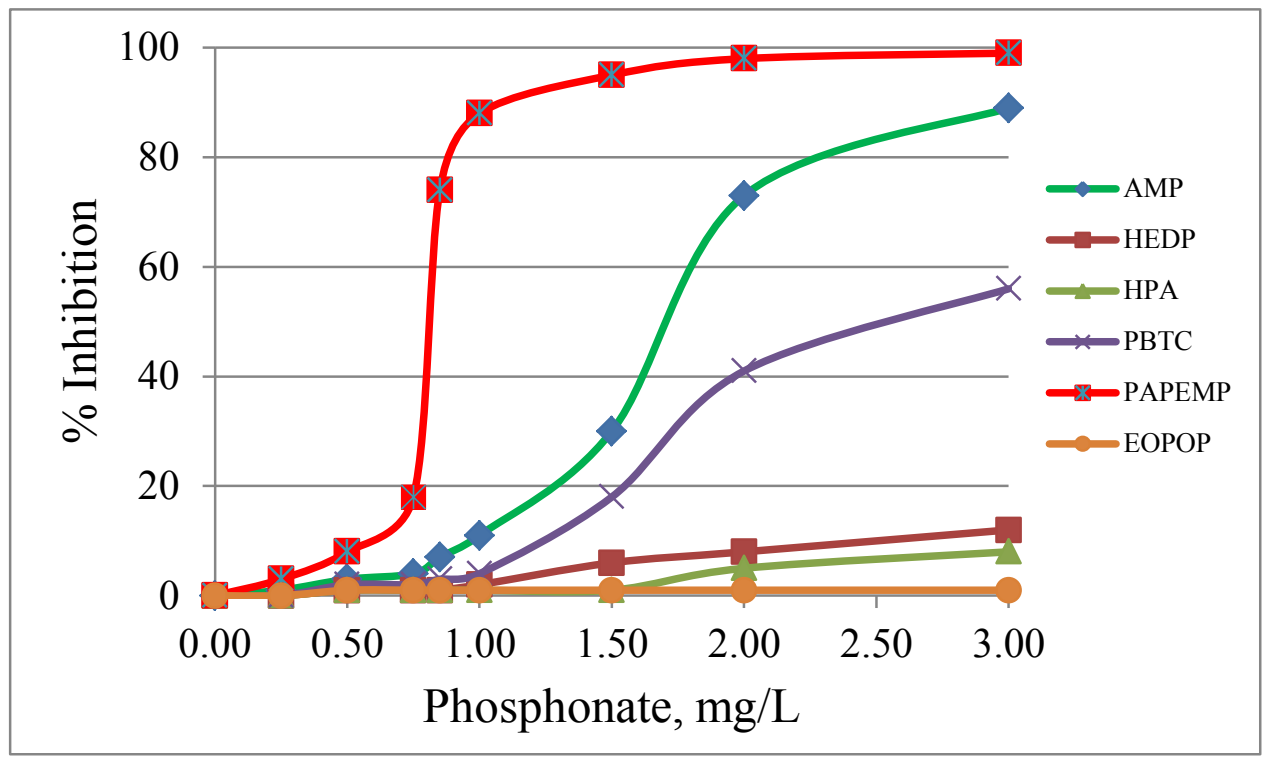

Figure 3. Plots of gypsum inhibition (\%) in the presence of varying concentration of phosphonates.

Several investigators have studied the influence of phosphorus containing compounds such as polyphosphates and phosphonates on gypsum crystallization in aqueous systems. Results of these studies reveal that performance of these compounds depends not only on the precipitation conditions but also on the structure of phosphorous containing compounds. Liu and Nancollas [22], in their seeded growth study on the evaluation of various phosphonates as gypsum inhibitors, reported that HEDP exhibits poor performance compared to AMP. It is worth noting that where as HEDP showed poor inhibitory activity compared to AMP for gypsum precipitation, HEDP has been reported to be an excellent inhibitor for strontium fluoride [23] and hydroxyapatite [24].

The performance of phosphonates as inhibitors for calcium carbonate $\left(\mathrm{CaCO}_{3}\right)$ system has been reported. Results of this study reveal that performance of phosphonates depends on the concentration of the phosphonates present in the $\mathrm{CaCO}_{3}$ supersaturated solution [25]. For example, performance trend observed in the presence of $5.0 \mathrm{mg} / \mathrm{L}$ phosphonates for $\mathrm{CaCO}_{3}$ system (at 180x saturation) is: HEDP $\geq$ AMP $>>$ PBTC. However, at higher concentrations of phosphonates (i.e., $40 \mathrm{mg} / \mathrm{L}$ ) the performance trend observed is: PBTC $>>$ $\mathrm{HEDP} \geq \mathrm{AMP}$. The improved performance of PBTC at higher $\mathrm{CaCO}_{3}$ saturation has been 
attributed to better tolerance of PBTC to calcium ions. Thus, for cooling water systems operating at higher cycles of concentration, PBTC is a better inhibitor for $\mathrm{CaCO}_{3}$ and $\mathrm{CaSO}_{4} \cdot 2 \mathrm{H}_{2} \mathrm{O}$ than HEDP. Thus, the performance of phosphonates as precipitation inhibitors depends on the type of the sparingly soluble salts being inhibited.

\subsubsection{PAPEMP/PAA blend performance}

Rahman et al. [26] using the seeded growth technique investigated the influence of ethylenediamine tetra(methylene phosphonic acid), ENTMP, PAA, and ENTMP/PAA blend on the crystal growth of calcium fluoride. It was shown that although PAA and ENTMP were effective crystal growth inhibitors, but the combined retarding effect of their mixtures was less than the sums of those of the components. It was proposed that molecular interference between the adsorbates facilitating diffusive access to calcium and fluoride ions to the growth sites through the disruptive adsorption layer. Thus, it is clear that influence of phosphonate on the performance of polymer as precipitation inhibitor depends not only on the type of the inhibitor but also on scaling system being inhibited.

To study the impact of PAPEMP on PAA performance several precipitation experiments were conducted in the presence of varying dosages of PAA, PAPEMP, and PAA/PAPEMP (1:1 ratio blend). Results presented in Fig. 4 clearly show that addition of PAPEMP increases the performance of PAA. For example, $\% I$ values obtained in the presence of $0.50 \mathrm{mg} / \mathrm{L}$ of PAA and PAPEMP when tested alone are $10 \%$ and $6 \%$ respectively compared to $72 \%$ obtained with $1.0 \mathrm{mg} / \mathrm{L}$ of PAA/PAPEMP blend. It is interesting to note that $\% I$ value obtained for $1.0 \mathrm{mg} / \mathrm{L}$ PAA is $40 \%$ compared to $72 \%$ obtained with $1 \mathrm{mg} / \mathrm{L}$ PAA/PAPEMP blend.

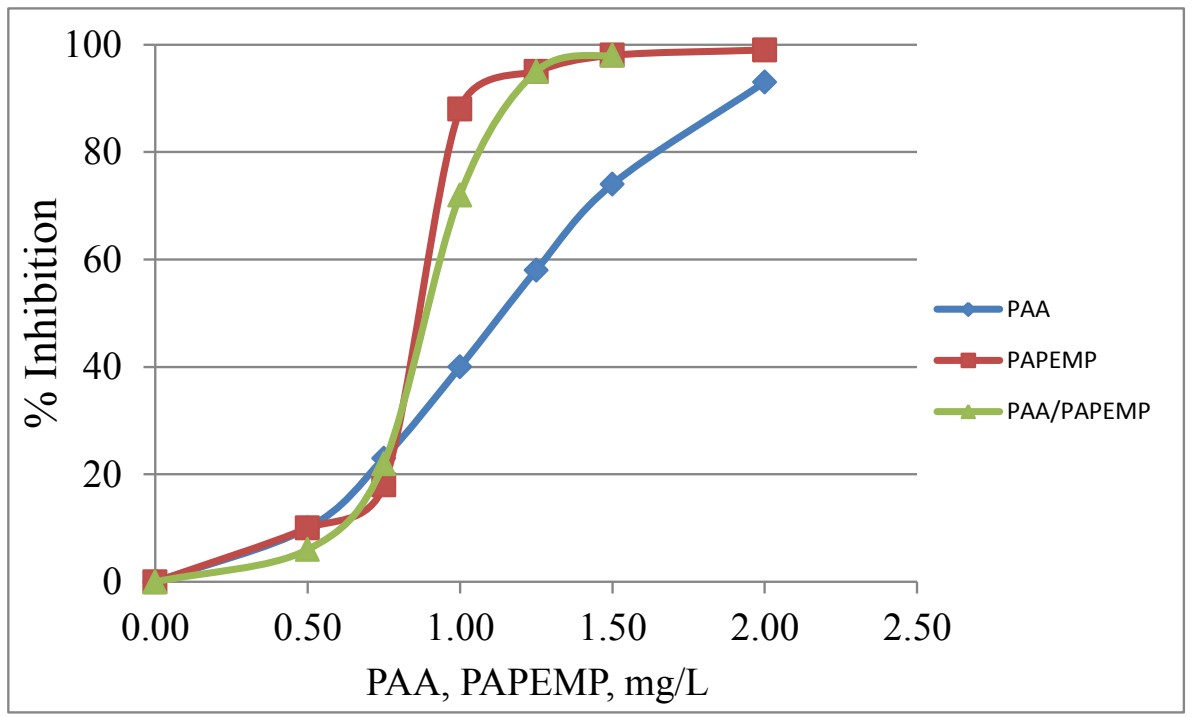

Figure 4. Plots of gypsum inhibition in the presence of PAA, PAPEMP, and PAA/PAPEMP blend. 


\subsection{Calcium-inhibitor (Ca-I) salt precipitation}

The control of mineral scale, suspended matter, and corrosion in water treatment, laundry, and oil and gas production, desalination, etc., by various additives has been well researched [1]. However, the interactions of various treatment additives with hardness ions have been mostly overlooked. One of the major concerns of the industrial water technologists is compatibility or tolerance limit of the anionic polymeric or non-polymeric precipitation inhibitors, hereafter called (I) with hardness ions (i.e., $\mathrm{Ca}, \mathrm{Mg}$ ). The tolerance or compatibility of an inhibitor is defined as the maximum amount of inhibitor that can be added to the water system without significant precipitation of M-I salts. If the compatibility is poor and the dosage of the formulation used is higher than the recommended level, not only does M-I precipitation occurs, but also the overall scale formation becomes faster and could lead to many troubles, e.g., early shutdown, wasted time, reduced productivity, and low profitability.

The tolerance of various phosphonates with $\mathrm{Ca}$ ions, was investigated from measurements of the turbidity of the respective solutions. Figure 5 presents the typical "\% transmittance" readings as a function of phosphonate concentration. The inflection point in the transmittance-inhibitor profile was used to calculate the point of onset of turbidity. Figure 5 shows compatibility data obtained for various phosphonates $(250 \mathrm{mg} / \mathrm{L}$ $\left.\mathrm{Ca}, \mathrm{pH} 9.00,25^{\circ} \mathrm{C}, 30 \mathrm{~min}\right)$. The reproducibility was satisfactory $( \pm 7 \%)$ as may be seen from the coincidence of the curves for PBTC. The compatibility value calculated for AMP was $27 \pm 2 \mathrm{mg} / \mathrm{L} \mathrm{HEDP} / 250 \mathrm{mg} / \mathrm{L} \mathrm{Ca}$. The compatibility data for HEDP are shown as well in Fig. 5. As may be seen, AMP is more compatible than HEDP. In order to study the impact of $-\mathrm{COOH}$ group present in the phosphonates, compatibility experiments were carried out with varying dosages of HPA and PBTC. As presented in Fig. 5, incorporation of $-\mathrm{COOH}$ and/or increase in chain length in phosphonates increases $\mathrm{Ca}$ ions compatibility of phosphonates. For example, $\mathrm{Ca}$ ions compatibility values obtained for HPA are $33 \mathrm{mg} / \mathrm{L}$ compared to $95 \mathrm{mg} / \mathrm{L}$ for PBTC. Figure 5 also presents $\mathrm{Ca}$ ions compatibility value for PAPEMP and PEOPO, a non-phosphonate containing additive. The excellent tolerance shown by PAPEMP may be attributed to the presence of poly(ether) group in PAPEMP. Based on their $\mathrm{Ca}$ ions tolerance these phosphonates can be ranked (in descending order) as follows: PAPEMP $>>$ PBTC $>$ HPA $>$ AMP $>$ HEDP.

\subsection{Gypsum crystals morphology characterization}

Crystals formed during the gypsum precipitation were filtered using $0.22 \mu \mathrm{m}$ membrane filter paper and the samples were air dried. Optical microscopy was used to study the effect of PAA and PAPEMP on crystal structure. Figure $6(A)$ shows optical micrograph of gypsum crystals formed in the absence of additive. As may be seen gypsum crystals are thin tubular cells and needles exhibiting monoclinic symmetry. In Fig. $6(B),(C)$, and $(D)$, gypsum crystals grown in the presence of PAA, PAPEMP, and PAA/PPAPEMP blend are presented. As illustrated, crystals grown in the presence of additives are markedly modified and lack total absence of tubular cell shaped gypsum with reduced size. 


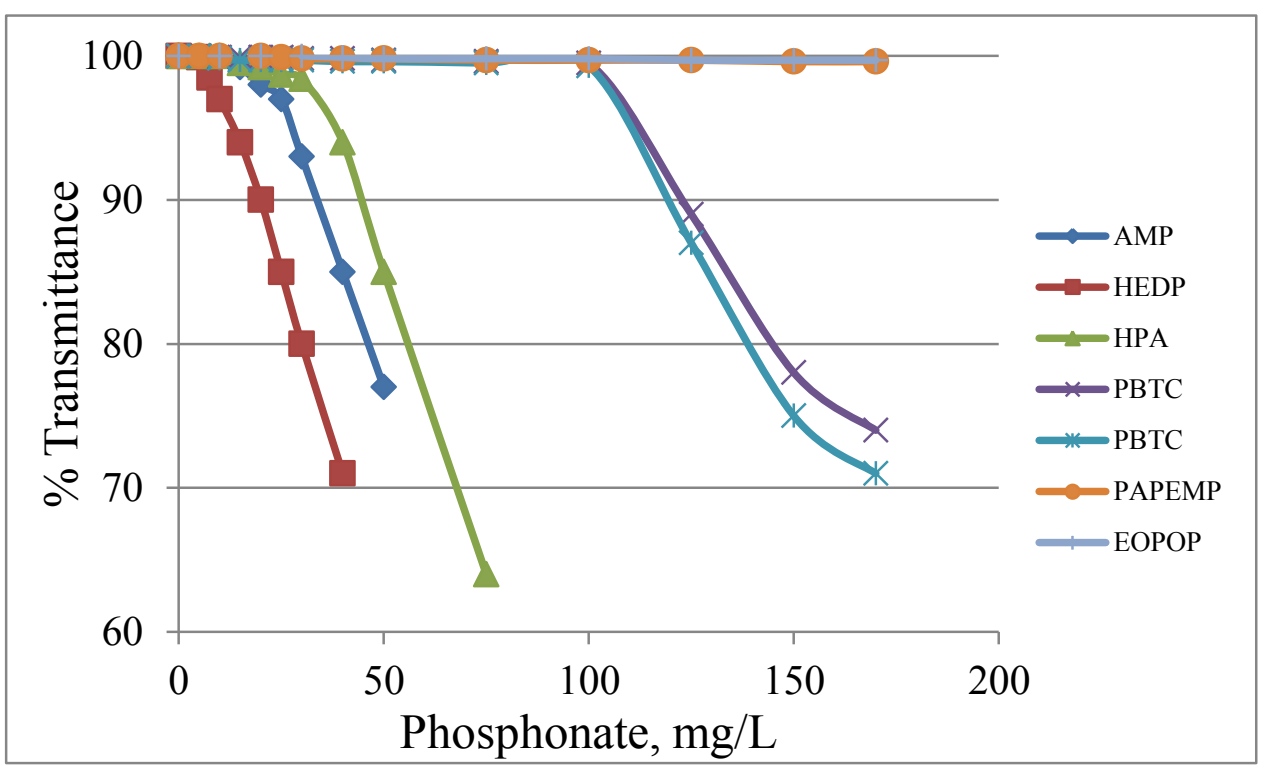

Figure 5. Plots of $\%$ transmittance versus phosphonate concentration for calcium ion tolerance.

\section{Conclusions}

The conclusions drawn from this study are as follows:

1) Homopolymers, e.g., poly(acrylic acid), poly(methacrylic acid) containing carboxyl group $(-\mathrm{COOH})$ exhibit good to excellent performance in inhibiting gypsum precipitation.

2) Homopolymers, e.g., lignosulfonate containing $-\mathrm{SO}_{3} \mathrm{H}$ group and poly(2-ethyloxazoline) containing non-ionic group, are ineffective gypsum scale inhibitors.

3) Inhibitor concentration is critical to the performance of gypsum inhibitors. An increase in inhibitor concentration results in a significant increase in the inhibition of gypsum precipitation.

4) Among the various phosphonates, e.g., aminotris(methylene phosphonic acid), AMP; hydroxyphosphono acetic acid, HPA; 2-phosphonobutane 1,2,4-tricarboxylic acid, PBTC; hydroxyethyliidine 1,1-diphosphonic acid, HEDP; polyamino polyether phosphonic acid, PAPEMP investigated, PAPEMP shows the best performance as gypsum precipitation inhibitor.

5) Addition of PAPEMP to PAA exhibits unexpected synergistic performance.

6) PAPEMP compared to other phosphonates tested shows the best $\mathrm{Ca}$ ion tolerance.

7) Addition of PAA and PAPEMP to gypsum supersaturated solutions shows marked morphological changes to gypsum crystals.

\section{Acknowledgement}

The authors would like to thank the Division of Mathematics and Sciences, Walsh University, for providing the research facilities needed for the above study. 

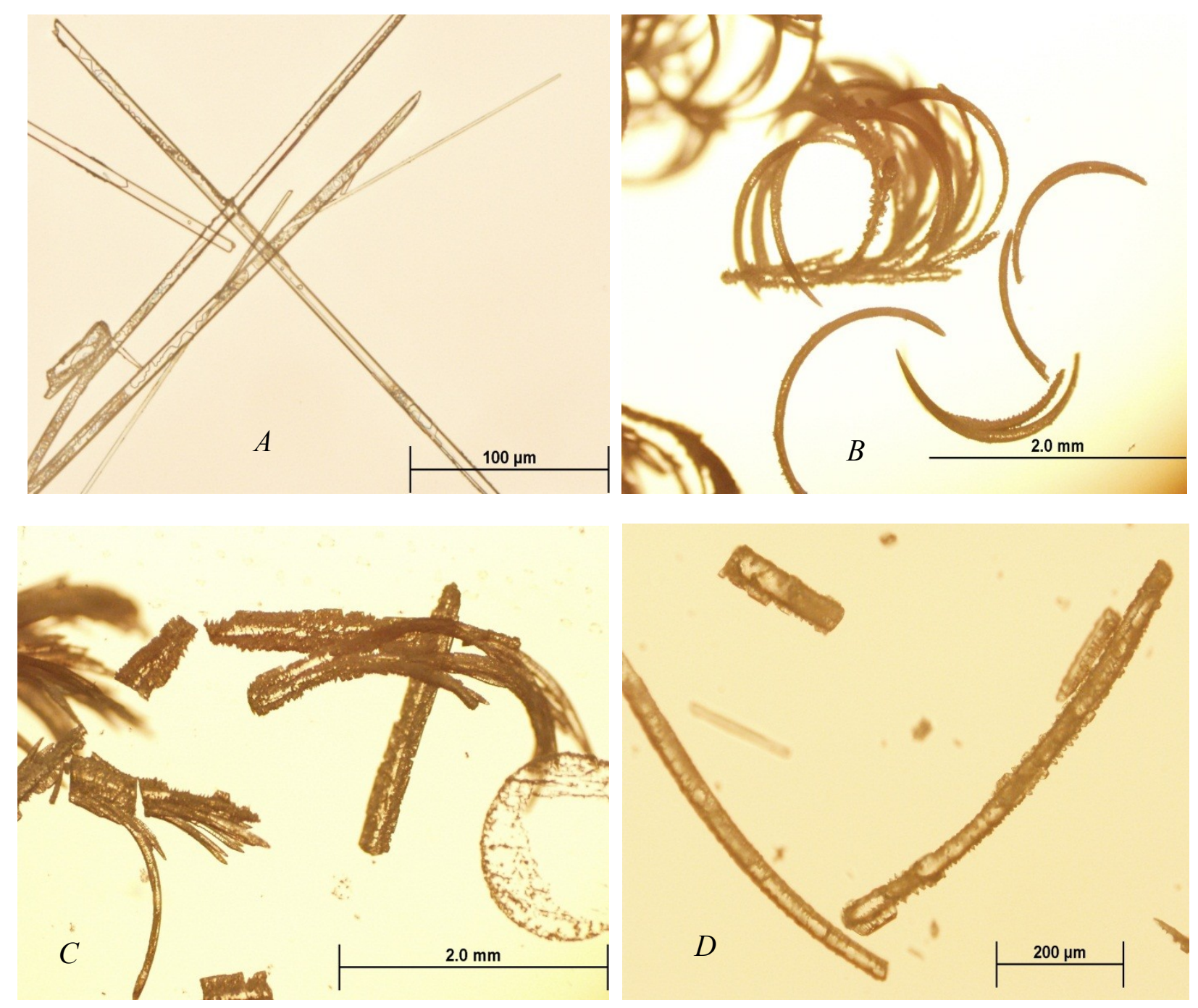

Figure 6. Optical micrographs of gypsum crystal grown in the absence of inhibitor $(A)$, in the presence of $1.0 \mathrm{mg} / \mathrm{L}$ PAA $(B), 0.75 \mathrm{mg} / \mathrm{L}$ PAPEMP $(C)$, and $1.0 \mathrm{mg} / \mathrm{L}$ of PAA/PAPEMP $(D)$.

\section{References}

1. R. W. Zuhl and Z. Amjad, Ch. 5, in The Science and Technology of Industrial Water Treatment, ed. Z. Amjad, CRC Press, Boca Raton, FL, 2010.

2. W. W. Frenier and M. Ziauddin, Formation, Removal, and Inhibition of Inorganic Scale in the Oilfield Environment, Society of Petroleum Engineers, Richardson, TX, 2008.

3. D. Hasson, H. Shemer and A. Sher, Indust. Chem. Engin. Res., 2011, 50, 7601.

4. G. H. Nancollas, Ceramic Transaction, 1988, 1A, 1.

5. M. Lahav and L. Leiserovitz, J. Phys. D: Appl. Phys., 1993, 26, 22.

6. Z. Amjad, Ch. 16, in Calcium Phosphates in Biological and Industrial Systems, Ed.

Z. Amjad, Kluwer Academic Publishers, Boston, MA, 1998.

7. Z. Amjad, Tenside Surfactants Detergents, 1999, 36, 162. 
8. E. B. Smyk, J. E. Hoots, K. P. Fivizzani and K. E. Fulks, Corrosion/88, NACE, Houston, TX, 1988, paper No. 14.

9. Z. Amjad, J. Pugh, J. Zibrida and R. Zuhl, Mater. Perform., 1999, 36, 2.

10. Z. Amjad, Desalination Water Treatment, 2012, 37, 268.

11. M. Oner, O. Doga, and G. Oner, J. Crystal Growth, 1998, 186, 427.

12. O. Dogan, E. Akyol, S. Baris and M. Oner, in Advances in Crystal Growth Inhibition Technologies, Ch. 14, Ed. Z. Amjad, Kluwer Academic/Plenum Publishers, New York, NY, 2000.

13. B. Senthilmurugan, B. Gosh, S. S. Kundu, M. Haroun and B. Kameshwari, J. Petrol. Sci. Engn., 2010, 75, 189.

14. Y. Tang, W. Yang, X, Yin, Y. Liu, P. Yin and J. Wang, Desalination, 2008, 228, 55.

15. S. B. Ahmad, M. M. Tilili and M. B. Amor, Crys. Res. Technol., 2008, 43, 935.

16. Z. Amjad and J. Hooley, J. Colloid Interface Sci., 1986, 111, 496.

17. Z. Amjad, Tenside Surfactants Detergents, 1999, 36, 50.

18. K. D. Demadis, E. Neofotisou, E. Mavredaki, M. Tsiknakis, E. M. Saringiannidou and S. D. Katarachia, Desalination, 2005, 179, 281.

19. J. C. Cowan and D. J. Weintritt, Water Formed Deposits, Gulf Publishing Company, Houstan, TX, 1975.

20. J. Zhang, A. Ebrahimpour and G. H. Nancollas, J. Colloid Interface Sci., 1992, 152, 132.

21. A. Abrahimpour, F. H. Ebertine, G. Sethuraman and G. H. Nancollas, in Mineral Scales Formation and Inhibition, Ch. 24, Ed. Z. Amjad, Plenum Publishing Corporation, New York, NY, 1995.

22. S. T. Liu and G. H. Nancollas, J. Colloid Interface Sci., 1973, 44, 422.

23. S. M. Hamza and G. H. Nancollas, J. Chem. Soc., Faraday Trans. 1, 1982, 81, 1833.

24. Z. Amjad, Langmuir, 1987, 3B, 1063.

25. Z. Amjad and R. W. Zuhl, The Use of Polymers to Improve Control of Calcium Phosphonate and Calcium Carbonate in High Stressed Cooling Water Systems, paper presented at Association of Water Technologies 2004 Annual Convention, Nashville, TN.

26. A. A. Rahman, M. Salem and G. H. Nancollas, in Mineral Scale Formation and Inhibition, Ch. 11, Ed. Z. Amjad, Plenum Press, New York, NY, 1995. 